\title{
EXAMINATION OF HEAT PIPE BASED SYSTEMS FOR ENERGY-EFFICIENT REDUCTION OF THERMALLY INDUCED ERRORS IN MACHINE TOOLS
}

\author{
I. Voigt ${ }^{1 *}$, W.-G. Drossel ${ }^{1,2}$ \\ ${ }^{1}$ Professorship for Adaptronics and Lightweight Design, Technische Universitaet Chemnitz, 09107 Chemnitz, \\ Germany \\ ${ }^{2}$ Fraunhofer Institute for Machine Tools and Forming Technology, Noethnitzer Straße 44, 01187 Dresden, Germany \\ *Corresponding author; e-mail: Immanuel.voigt@mb.tu-chemnitz.de
}

\begin{abstract}
Variable heat sources in machine tools lead to unsteady displacement fields and hence necessitate temperature control in order to maintain the required positioning accuracy. Adding passive components that redistribute heat through heat storage and heat transport within the machine tool is one approach to compensate for thermal errors. While including latent heat storage components reduces the machine response to heat inputs in a certain temperature range, highly conductive elements like heat pipes provide the option to transport heat losses to environmental air or further components. Thereby, the temperature field around heat emitting machine components can be altered aiming for a reduction of thermal displacements of the tool center point. In order to guarantee the efficacy of corresponding compensation systems in machine tools, the performance of heat pipes under accelerating forces has to be determined. The present paper presents findings of experimental investigations on translationally moved heat pipes conducted on a linear direct drive based test rig. A simulation approach for modeling the heat transfer limits of heat pipes is proposed providing a high compatibility with finite element models. Different scenarios for the use of heat pipes in machine tools are demonstrated and evaluated by means of numerical results.
\end{abstract}

\section{Keywords:}

thermal error; machine tools; heat pipe; latent heat storage; heat redistribution

\section{INTRODUCTION}

Thermal issues in machine tools have been addressed comprehensively in literature and industry in the last years proving the importance of the topic. As stated in [Putz 2018], ninety percent of manufacturers, which participated in the underlying survey, take corrective, compensatory and control-integrated actions to reduce thermal errors. Consequently, a wide variety of different solution approaches has been developed to reduce thermally induced errors. A common approach is the use of cooling systems to control the thermal machine tool behaviour [Brecher 2012]. Also, materials of low thermal expansion such as carbon fiber reinforced plastic are employed as a technique to overcome thermal errors [Kono 2019]. Another frequently used compensation approach is to readjust the axes positioning based on models that use data obtained by measurement and simulation [Fraser 1998; Jedrzejewski 1992; Thiem 2017]. A broad overview over existing compensation methods can be find in [Ramesh 2000] and [Mayr 2012].

It can be concluded that thermally induced TCP displacements are encountered by compensation methods that usually lead to an increased energy input or increased effort because of additional measurement and simulation tools. Especially cooling systems account for a significant portion of the energy use of machine tools. In [Baumler 2011], the share of the cooling system on the overall energy consumption of a machining centre is given to be around $20 \%$. However, alongside the reduction of thermal error of machine tools another important aspect of thermal issues in machine tools is the reduction of energy input in the context of an adequate overall energy balance. Therefore, it is of great relevance to examine novel compensation approaches that aim for an improved thermal machine tool behaviour without further increasing the overall energy consumption.

This paper presents an approach for energy-efficient compensation of thermal errors in machine tools using heat pipe based systems. Heat pipes are passive heat transfer devices with very low thermal resistance that are used in a wide variety of application fields, such as thermal control of computer systems and solar cells. [Pastukhov 2007; Vasiliev 2005]. The effective thermal conductivity of heat pipes can reach up to the order of $10^{5} \mathrm{~W} /(\mathrm{m} \mathrm{K})$ [ElNasr 1996]. A wide range of different forms and types of heat pipes has been presented in literature [Reay 2014]. 


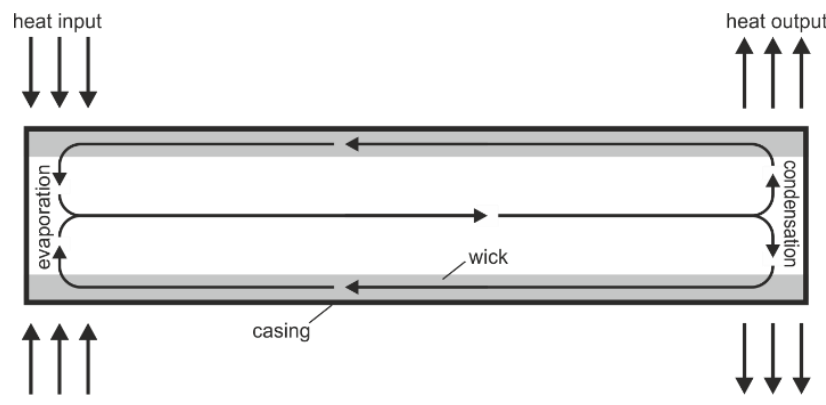

Fig. 1: Schematic diagram of a heat pipe.

The exceptional heat transfer characteristics of heat pipes are based on a two-phase cycle of a working fluid within a hermetically sealed, typically tubular vessel, as shown in Fig. 1. In many cases, water is used as working fluid. Heat applied to the evaporator section of the heat pipe leads to the vaporization of the working fluid. Due to the resulting pressure difference, the gaseous phase flows to the condenser section where it condenses releasing its phase change enthalpy to the provided heat sink. The heat pipe contains a wick structure providing a capillary pressure that forces the liquid phase back to the evaporator section. Typical wicks are sintered, mesh and grooved wicks.

The presented work focuses on the concept of redistributing heat in machine tools using heat pipes. Recent investigations demonstrated the efficacy of latent heat storage components for buffering heat losses in feed drive systems. In that way, heat can be redistributed temporally [Voigt 2018]. By applying heat pipes to machine tool components it is aimed to transport heat spatially within the machine tool and its environment, in order to reduce local temperature peaks. Studies on the use of heat pipes in machine tools mainly address the cooling of spindles [Denkena 2018; Judd 1994; Wegener 2017]. In order to design heat pipe based compensation systems for different machine tool components that account for limited installation space and restrictions regarding the warm-up period of the machine, it is essential to provide efficient and precise design tools.

A central aspect of the proposed concept is the amount of heat that can be transported by heat pipes in machine tools. Hence, experimental investigations on the heat transfer characteristics of heat pipes are illustrated. Based on the findings of those experiments, a simple heat pipe model is presented. The model uses a thermal resistance representation of the heat pipe and can easily implemented in Finite Element (FE) models. This paper demonstrates possible ways to integrate heat pipes in machine tools for temperature control and investigates the efficacy of one concept numerically by means of $\mathrm{FE}$ simulation of a corresponding system.

\section{EXPERIMENTAL EXAMINATION OF HEAT PIPE HEAT TRANSFER CHARACTERISTICS}

The thermal behaviour of a heat pipe highly depends on its orientation as gravity-opposed orientations hinder the liquid flow. Depending on the specific geometric dimensions and the wick structure, heat pipes can, to some extent, realize gravity-opposed backflow of the liquid phase to the evaporator section. As the heat transfer properties of heat pipes cannot be quantified by a single thermal conductivity value, heat pipe manufacturers often do not provide information on the heat pipe performance for different orientations. Therefore, the design of a set-up for experimental characterization of heat pipes is illustrated in this chapter. The aim of these experiments is to quantify the thermal resistance of a heat pipe for different heat inputs as well as its heat transfer limits.

\subsection{Theoretical considerations}

The heat transfer properties of heat pipes are often expressed by means of an effective thermal conductivity. The heat pipe performance however depends on the pressure difference between evaporator and condenser section. Consequently, the thermal heat pipe behaviour cannot be described precisely by means a single value.

Due to the mainly one-dimensional heat transfer in a heat pipe, the heat flow $\dot{Q}$ transferred along a temperature gradient $\Delta T$ can be expressed by the thermal resistance

$R_{t}=\frac{\Delta T}{\dot{Q}}$

The thermal resistance of a heat pipe usually is not constant. In order to provide reliable physical parameters that represent the heat pipe for different application scenarios, the thermal resistance has to be obtained as a function of heat flow and inclination. Furthermore, the heat transfer limits need to be quantified. For the operation of a heat pipe it is essential that the capillary pumping pressure $\Delta p_{c, \max }$ is higher than the total pressure drop in the heat pipe. According to [Reay 2014], for correct heat pipe operation

$\Delta p_{c, \max } \geq \Delta p_{l}+\Delta p_{v}+\Delta p_{g}$

has to apply where $\Delta p_{l}$ is the pressure drop required to return the liquid to the evaporator, $\Delta p_{v}$ the pressure drop necessary to cause the vapour to flow to the condenser and $\Delta p_{g}$ the pressure difference due to the hydrostatic head of liquid depending on the heat pipe inclination. If this condition is not met, the fluid circulation stops leading to a dry-out of the evaporator. In this paper, the heat pipe transfer limit is aimed to be estimated by means of a highly increased thermal resistance occurring at a critical heat input value.

Another influence on the heat pipe behaviour to be investigated is the effect of motion. Machine tools exhibit unsteady motion profiles. The occurring acceleration forces potentially affect the performance of heat pipes in corresponding systems. It is expected that the acceleration forces have an impact on the two-phase fluid circulation in the heat pipe in a manner that lowers or increases the heat transfer limits depending on the heat pipe and process parameters. To examine the motion influence on the heat pipe behaviour, experiments were conducted on an experimental set-up at standstill and during movement.

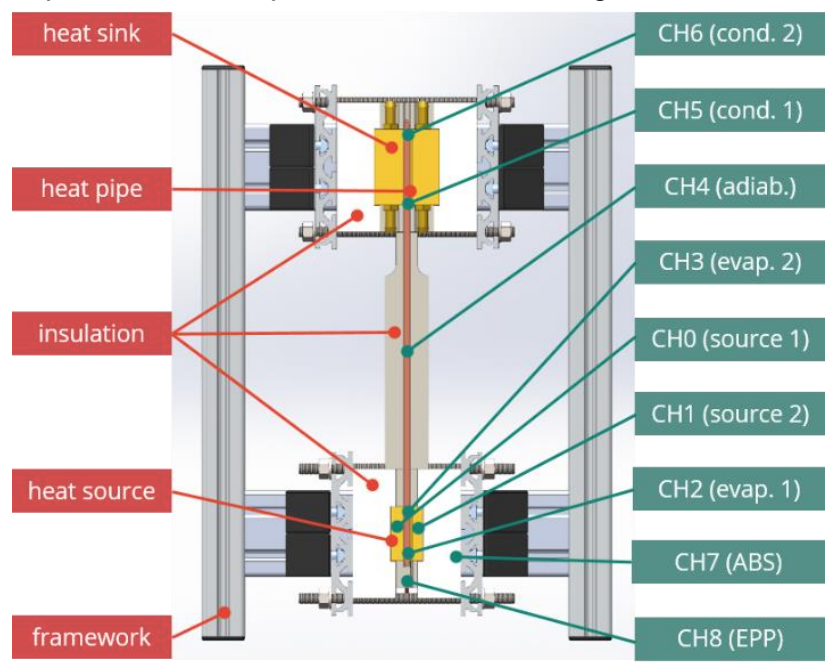

Fig. 2: Heat pipe assembly and sensor positions. 


\subsection{Experimental set-up}

The central element of the experimental set-up is an aluminum framework in which the heat pipe is fixed and thermally loaded. The evaporator section of the heat pipe is clamped between two copper elements that contain one cartridge heater each. Similarly, the condenser section of the heat pipe is clamped between two copper elements. These copper elements contain two cylindrical channels each and are connected to a thermostat with a circulation pump. Silicon oil is used to cool down the copper elements. Both heat source and heat sink assemblies are surrounded by acrylonitrile butadiene styrene (ABS) components used as thermal insulation. The heat pipe was insulated by using expanded polypropylene (EPP). As the heat pipe characteristics are aimed to be investigated for different orientations, the assembly of heat pipe, heat source and heat sink can be rotated within the aluminum framework to adjust different inclination angles. For temperature measurement within the cartridge heaters thermocouples type $\mathrm{J}$ were used $(\mathrm{CH} 0$ and $\mathrm{CH} 1)$. Thermocouple of type $\mathrm{K}$ were attached to the evaporator, adiabatic and condensor section of the heat pipe as well as the ABS and EPP insulation. The heat pipe assembly and the sensor positions are illustrated in Fig. 2. An additional sensor ( $\mathrm{CH} 9)$ was used to measure the ambient temperature. Figure 3 shows the heat pipe clamped between the copper blocks.

In order to provide acceleration forces to the heat pipe system within the motion scenario, the heat pipe assembly is mounted onto a linear direct drive. The entire experimental set-up can be seen in Fig. 4.

The temperature sensor data was logged by data aquisition module Omega OMB-DAQ-2416. For power supply the Aim-TTi QPX1200SP was used. The silicon oil cooling and circulation was done by the circulation thermostat LAUDA ECO Silver RE 420. The control of power input into the cartridge heaters as well as the status and set-point temperature of the cooling thermostat were controled within a LABVIEW environment. A commercially available heatpipe with sinter mesh was chosen for the experimental investigations. The heat pipe length equals $300 \mathrm{~mm}$ and the heat pipe diameter equals $8 \mathrm{~mm}$.

The first experiments have been conducted with deactivated feed drive (static test case). At the beginning of each measurement the oil temperature was set to $20^{\circ} \mathrm{C}$ and the circulation pump was activated. After a $30 \mathrm{~min}$ cooling period, a constant power supply was provided to the cartridge heaters until stationary state was reached. The temperature curves were defined to be stationary when the temporal fluctuation is found to be less than $0.5 \mathrm{~K}$ over the last $30 \mathrm{~min}$. The experiments were conducted for three different heat pipe inclinations $\delta$ :

- gravity-assisted orientation $\left(\delta=+90^{\circ}\right.$, heat source at the bottom),

- horizontal orientation $\left(\delta=0^{\circ}\right)$ and

- gravity-opposed orientation $\left(\delta=-90^{\circ}\right.$, heat source on top).

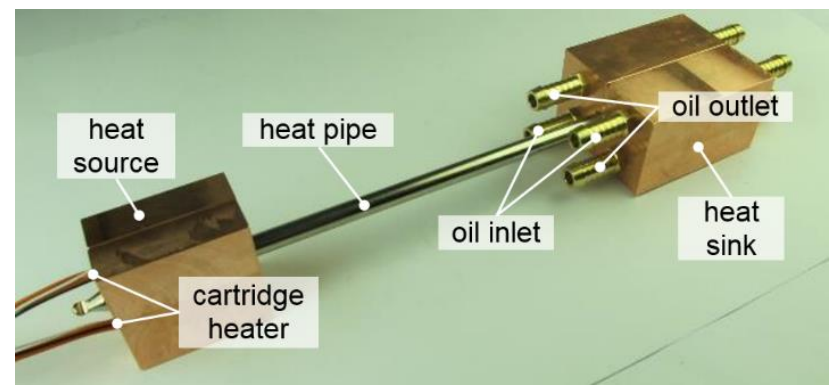

Fig. 3: Heat pipe with heat source and heat sink. MM Science Journal | 2021 | Special Issue on ICTIMT2021

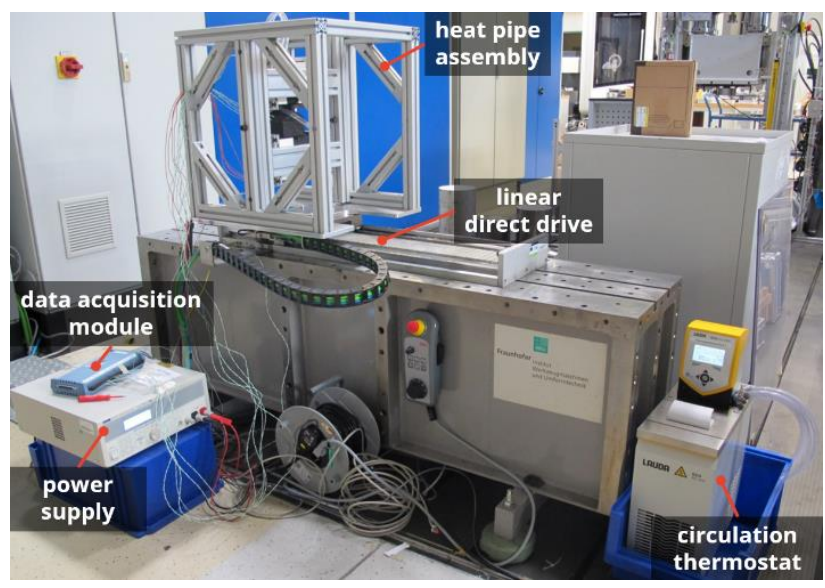

Fig. 4: Experimental set-up.

Afterwards, the experiments were conducted with active feed drive (dynamic test case). Throughout the dynamic measurements, the heat pipe assembly moved periodically between the axis positions of $200 \mathrm{~mm}$ and $500 \mathrm{~mm}$. Between those two positions, the system accelerates and decelerates at $5 \mathrm{~m} / \mathrm{s}^{2}$ and $-5 \mathrm{~m} / \mathrm{s}^{2}$, respectively. The feed motion profile used for the dynamic measurements is shown in Fig. 5. During the cooling periods with the heat sources switched off, the motor was at standstill.

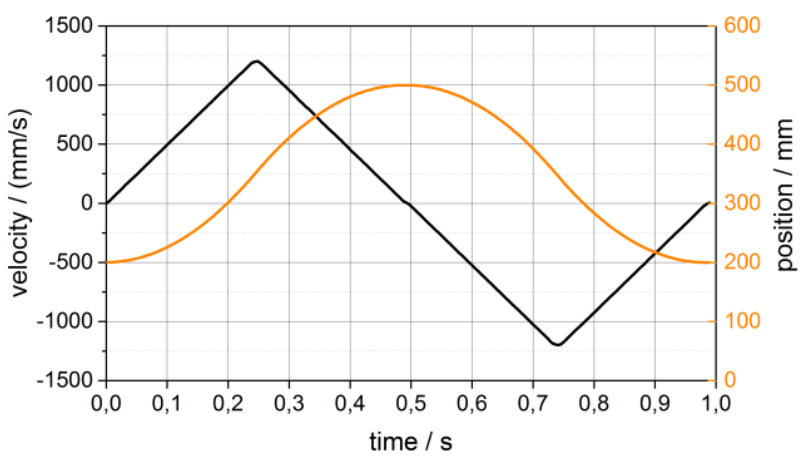

Fig. 5: Feed motion profile.

The heat transfer limit was defined as the heat flux for which stationary state was not reached after $240 \mathrm{~min}$ of heating. To avoid overheating of the set-up, a critical temperature of $100^{\circ} \mathrm{C}$ was defined. If any temperature sensor value exceeds this temperature, the heat supply is shut down.

\subsection{Results of heat pipe characterization}

In Fig. 6, exemplary temperature curves of the static test case at $\delta=+90^{\circ}$ are demonstrated. The temperature gradients between evaporator and condenser section of the heat pipe were obtained by the measurements and evaluated according to equation (1). For the heat source and heat sink temperatures the mean values of channels 2 and 3 and of channels 5 and 6 were used, respectively.

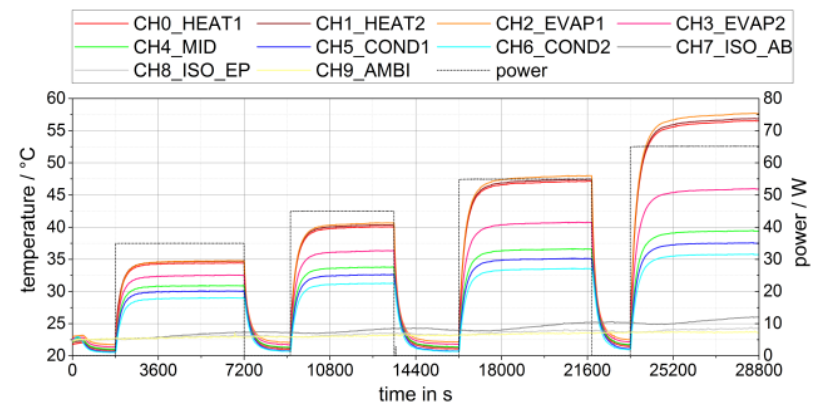

Fig. 6: Temperature curves for $+90^{\circ}$ and static test case at heat inputs between $35 \mathrm{~W}$ and $65 \mathrm{~W}$. 
The resulting thermal resistances as a function of the heat input as well as the temperature gradients between evaporator and condenser are illustrated in Fig. 7 . The resistance curve progressions for the different heat pipe orientations share similar characteristics. All curves exhibit a minimum value at a certain power level. At lower and higher power levels, the resistances are significantly higher than the respective minimum values. The heat transfer limits were found to be $85 \mathrm{~W}$ for gravity-assisted orientation (static and dynamic test case) and $12 \mathrm{~W}$ for gravityopposed orientation (static and dynamic test case). For horizontal orientation the heat transfer limit was obtained with $38 \mathrm{~W}$ for the static test case and $42 \mathrm{~W}$ for the dynamic test case. The minimum thermal resistance of the heat pipe equals $0.10 \mathrm{~K} / \mathrm{W}$ for gravity-assisted orientation (at $25 \mathrm{~W}$ ), $0.20 \mathrm{~K} / \mathrm{W}$ for horizontal orientation (at $14 \mathrm{~W}$ ) and $0.38 \mathrm{KW}$ for gravity-opposed orientation (at $5 \mathrm{~W}$ ). The results demonstrate a high dependency of the heat pipe performance on the orientation. The acceleration forces during movement do not have significant influence on the thermal resistance for gravity-assisted orientation. However, the thermal resistances at horizontal orientation are around $18 \%$ lower during movement. Close to the heat transfer limit the thermal resistance at dynamic state is around $40 \%$ lower as the thermal resistance at static state and the heat transfer limit at dynamic state is higher. For gravity-opposed orientation, the resistance curves are similar for heat inputs less than or equal to $6 \mathrm{~W}$. Between $7 \mathrm{~W}$ and $10 \mathrm{~W}$, the resistances are approximately $30 \%$ higher at dynamic state. At $12 \mathrm{~W}$ heat input, the dynamic value is around $9 \%$ lower than the static value.

a

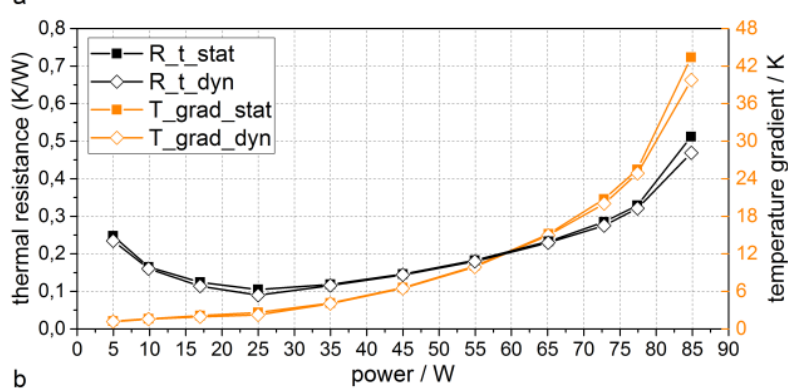

b
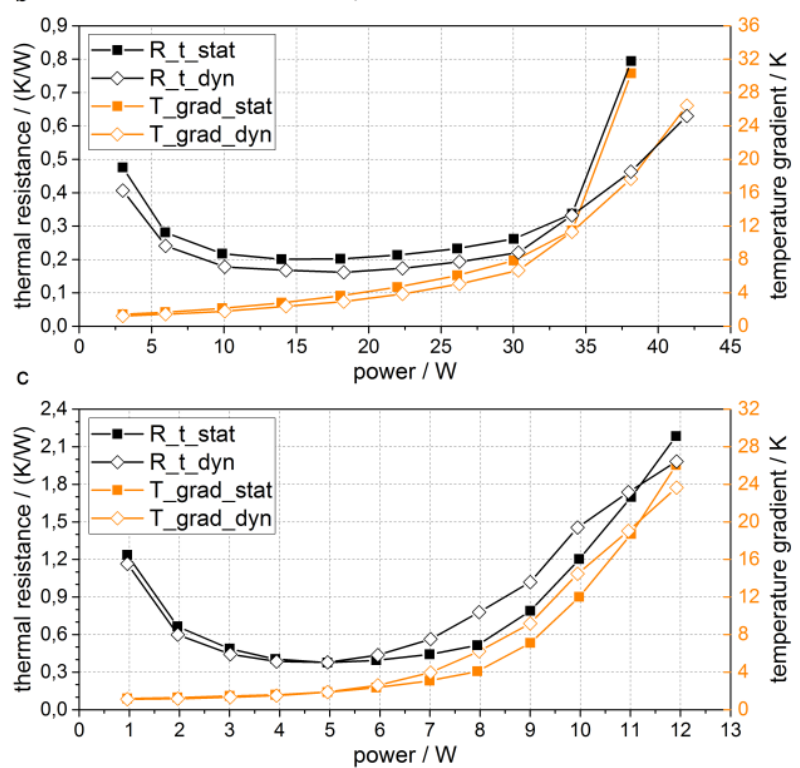

Fig. 7: Experimentally obtained thermal resistances and temperature gradients for different heat inputs and heat pipe orientations $\left(a: \delta=+90^{\circ}, b: \delta=0^{\circ}, c: \delta=-90^{\circ}\right)$.
In order to evaluate the repeatability of the results, the experiments were carried out three times for selected parameters. The highest deviations were observed at gravitiy-opposed orientation. It became clear that the heat pipe performance was affected by previous dry-out conditions of the evaporator. Consequently, the evaporator needed to be rewetted prior to each measurement at gravity-opposed orientation. The rewetting procedure was realized by heating the condenser section to $60^{\circ} \mathrm{C}$ and subsequent cooling. By means of the prewetting procedure the thermal resistance was reduced by around $61 \%$ for both static and dynamic tests. For gravity-assisted and horizontal orientations, this effect did not occur. The overall relative standard deviation of the obtained thermal resistance values was found to be below $5 \%$.

\section{HEAT PIPE MODELLING WITHIN FE MODELS}

The operation of a heat pipe is based on a two-phase flow of the working fluid. In order to model the complex fluid behaviour inside the heat pipe, computational fluid dynamics can be used. However, the complexity of regarding models leads to high calculation times and complex couplings with structural models. A CFD representation of heat pipes hence does not seem convenient for the use in thermal FE machine tool models. In addition, the exact pressure state and the phase boundaries inside the heat pipe are not relevant information for the overall machine tool simulation.

The modelling method applied in the present paper is based on the representation of the heat pipe as a thermal resistance network. This approach has been proposed by [Zuo 1998]. It considers a network of serially and parallel connected resistances describing the thermal behaviour of the different heat pipe sections.

In this paper, the heat pipe network representation is further simplified by describing the heat pipe by means of a single thermal resistance. That way, the results of the experimental heat pipe characterization can directly by implemented in FE models.

\subsection{FE model of the experimental set-up}

A thermal FE model of the set-up was built in commercial CAE software ANSYS to verify the heat pipe modelling method. The framework of the set-up was considered as thermally decoupled from the heat pipe assembly due to the ABS insulation surrounding the copper blocks. The FE model contains the evaporator and condenser section with the according insulation components. Instead of a solid contact between the two components, a one-dimensional element was defined between the contact faces of heat source and heat sink. The FE model is illustrated in Fig. 8.

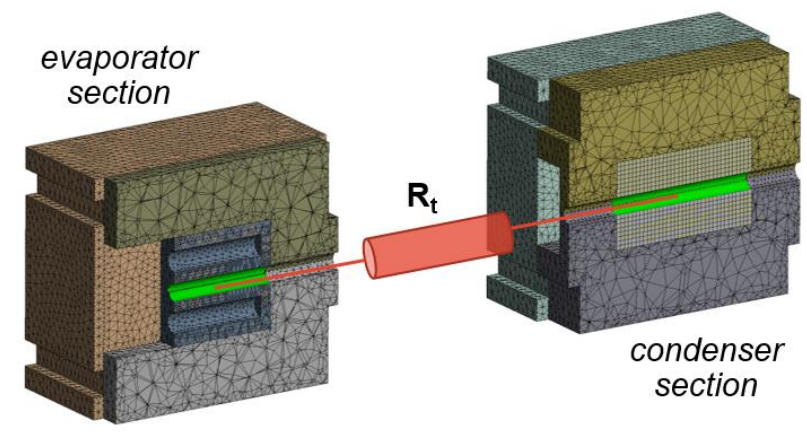

Fig. 8: FE-model of set-up.

To all free surfaces convection boundaries were applied. The FE model represents the static test case. Therefore, 
heat transfer coefficients for free convection were calculated and applied to the surfaces.

The convective heat transfer coefficients were calculated based on the empirical correlations given in [Klan 2006]. These formulae are given for different geometric scenarios and are used to obtain the Nusselt number $\mathrm{Nu}$. The Nusselt number leads to the convective heat transfer coefficient

$\alpha=\frac{\mathrm{Nu} \lambda}{l}$

with $\lambda$ as the thermal conductivity of air and $l$ as the characteristic length.

\subsection{Numerical results}

The temperatures at condenser and evaporator were obtained by means of steady-state and transient analysis. In Fig. 9, the numerically calculated temperatures at steady state are compared to the experimental data. The temperature values calculated by the simulation model are found to be in good accordance with the measured values. Figure 10 demonstrates an exemplary steady-state temperature field of the heat pipe assembly at horizontal orientation.

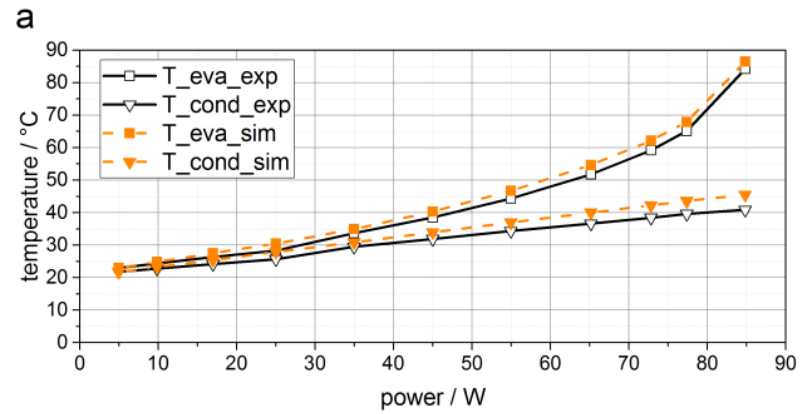

b

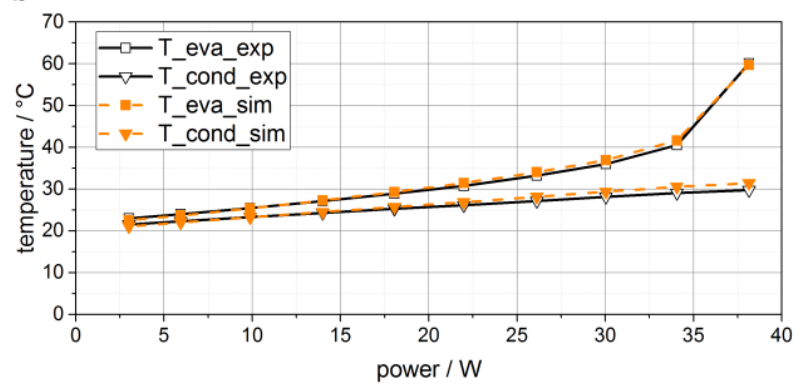

C

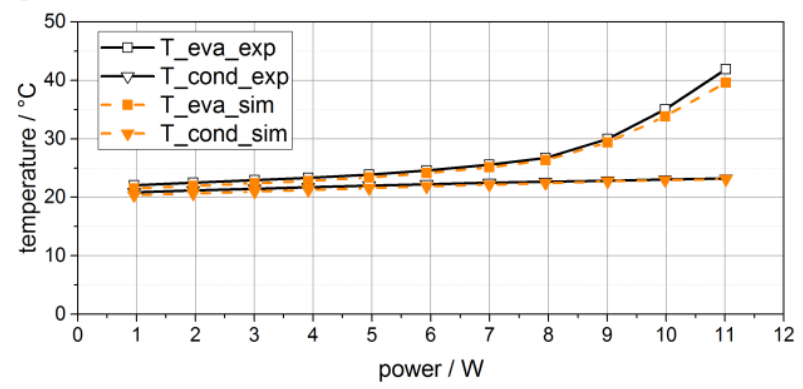

Fig. 9: Evaporator and condenser temperatures calculated by the FE model at steady state for different heat inputs and heat pipe orientations $\left(a: \delta=+90^{\circ}, b: \delta=0^{\circ}, c: \delta=-90^{\circ}\right)$ in comparison with the experimental data.

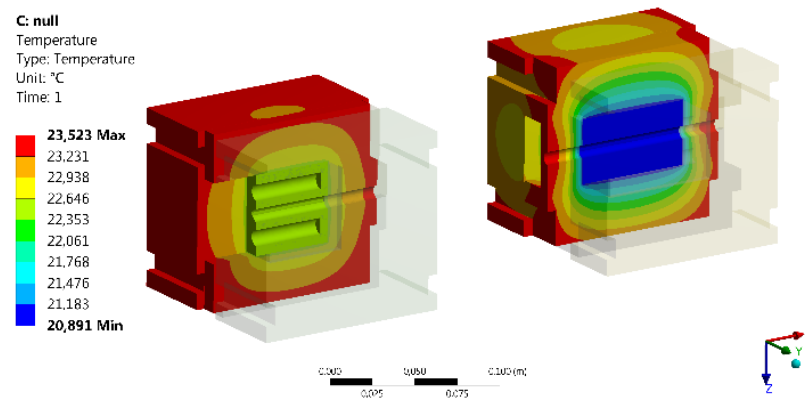

Fig. 10: Steady-state temperature field obtained by FE model at horizontal orientation for $3 W$ heat input.

In a second step, the simulation of the transient temperature fields was conducted. During the transient simulation, the same thermal resistance representation for the heat pipe was used as for steady-state simulation. Hence, the thermal capacity of the heat pipe was neglected. Exemplary temperature profiles for evaporator and condenser at gravity-opposed orientation are illustrated in Fig. 11. The comparison between simulation and measurement data shows a faster increase of the numerically obtained temperature profiles. The deviation between the numerically and experimentally obtained evaporator temperature was found to be up to $2.5 \mathrm{~K}$. This indicates that the modelled thermal capacity is too low. Consequently, the thermal capacity of the heat pipe needs to be considered in future FE analyses to further enhance the precision of the modelling approach.

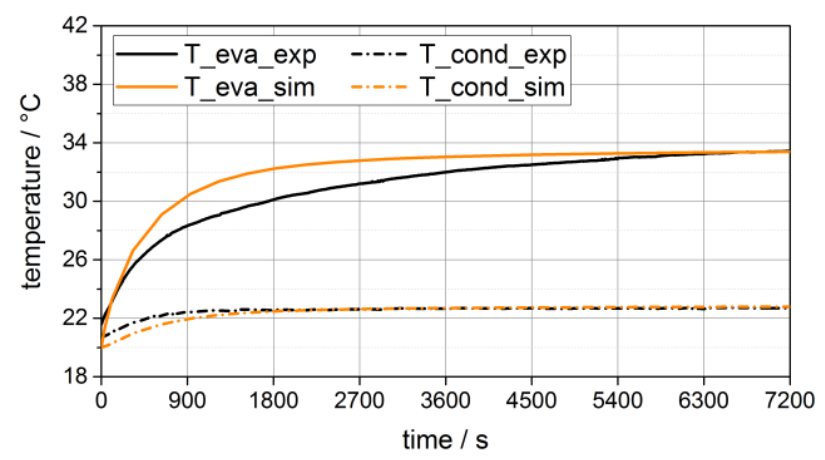

Fig. 11: Numerically and experimentally obtained transient evaporator and condenser temperatures at gravityopposed orientation for $10 \mathrm{~W}$ heat input.

\section{HEAT PIPE BASED THERMAL ERROR COMPENSATION}

After illustrating the characterization and modelling of heat pipes, this chapter focuses on considerations for heat pipe based concepts that can be used to create new heat transport paths within a machine tool with the goal of reducing thermally induced errors.

\subsection{Heat pipe based concepts for redistributing heat in machine tools}

As shown in the previous chapters, heat pipes provide heat transport capabilities that cannot be accomplished by means of basic heat conduction in solid structures of equivalent geometry. In comparison with active fluid systems, heat pipes transport less heat, but on the other hand do not require auxiliary components such as pumps. Furthermore, heat pipes are practically maintenance-free and provide a high cycle stability. Consequently, heat pipes can be an efficient tool to rearrange heat flows in machine tools. 
There are three heat pipe based application scenarios that are currently investigated:

1. Indirect integration of latent heat storage components.

2. Connecting heat sources to additionally integrated heat sinks.

3. Improving thermal exchange within machine tool components.

A recently investigated approach considers the increase of the heat capacity of machine tools in a certain temperature range by integrating latent heat storage components. This approach has been experimentally investigated for ball screw drives [Voigt 2019] and linear direct drives [Voigt 2018]. The implementation of this method in practice however faces the challenge of overcoming the lack of available installation space. Motors and components, that experience friction, are among the main heat sources in machine tools. To effectively manipulate the heat fluxes around these lossy components, a certain volume of installation space is needed. In many cases, there is not sufficient space for correspondent components. Heat pipes offer the possibility to place latent heat storage components in a certain distance to the heat source and at the same time provide a convenient thermal connection. That way, the available installation space for compensation components increases significantly.

Besides increasing the thermal capacity of machine tools, the increase of the machine surface area can lead to an improved thermal behaviour. This can be accomplished by the integration of heat sinks. As a result, more heat dissipates through convective heat transfer. The motion of the machine parts can hereby support the heat transfer to the ambient air by enhanced interaction between the solid surface and the moving air molecules. A possible drawback of this approach is the permanent increase of heat capacity of the machine tool that may lead to increased warm-up periods. For the heat sinks to operate situationally, thermal switches as proposed in [Schneider 2016] can be applied to the system. By using thermal switches, heat sinks can be connected to and disconnected from the heat source depending on the actual load situation.

The third scenario considers the application of heat pipes to reduce thermal gradients within machine components. This approach seems applicable for large machine components that exhibit a strongly inhomogeneous temperature field during machine operation. By attaching heat pipes between areas with high temperature differences, the thermal exchange between those parts can be enhanced.

In order to evaluate the efficacy of the heat redistribution through heat pipes, FE simulation can be used. An exemplary simulation for the second scenario is presented in the following section.

\subsection{Numerical investigation of a heat pipe based compensation concept}

An FE model was realized to estimate the effect of a heat sink connected to a machine tool through heat pipes. The model is based on a simplified geometry of a carriage moved by two linear motors, as shown in Fig. 12. The aim of this model is to simulate, how a heat sink connected to the carriage by five heat pipes affects the temperature field of the carriage. In addition, it is used to estimate the difference between a horizontal and two vertical designs of a corresponding heat pipe system.

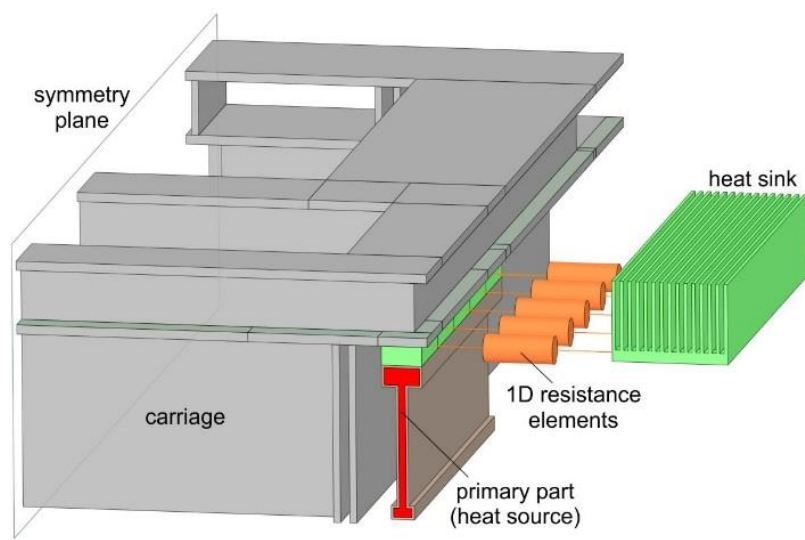

Fig. 12: FE model of carriage with linear motor, heat sink and one-dimensional resistance elements.

The primary part of the linear motor acts as the heat source. A constant heat loss of $200 \mathrm{~W}$ is defined for the core body of the primary part. The convective boundary conditions of the model assume a mean carriage velocity of $1 \mathrm{~m} / \mathrm{s}$. The convective heat transfer coefficients hence were calculated for the case of forced convection. The empirical formula given in [Gnielinski 2006] was used to calculate the Nusselt number for all free surfaces. The heat transfer coefficients were determined by using equation (3).

The carriage is approximately $0.9 \mathrm{~m}$ long and $0.7 \mathrm{~m}$ wide. Due to the symmetry, only half of the carriage is modelled. The material of the carriage as well as the heat sink is defined as an aluminium alloy. The core body of the primary part is defined as copper and its mantle is defined as epoxy resin. Between linear motor and carriage a copper body is defined. At the outer surface of this body five onedimensional resistance elements are attached connecting it to the heat sink.

The simulation was conducted for three different heat pipe inclinations: $\delta=+90^{\circ}, \delta=0^{\circ}$ and $\delta=-90^{\circ}$. The respective experimentally obtained resistance values are assigned to the one-dimensional resistance elements.

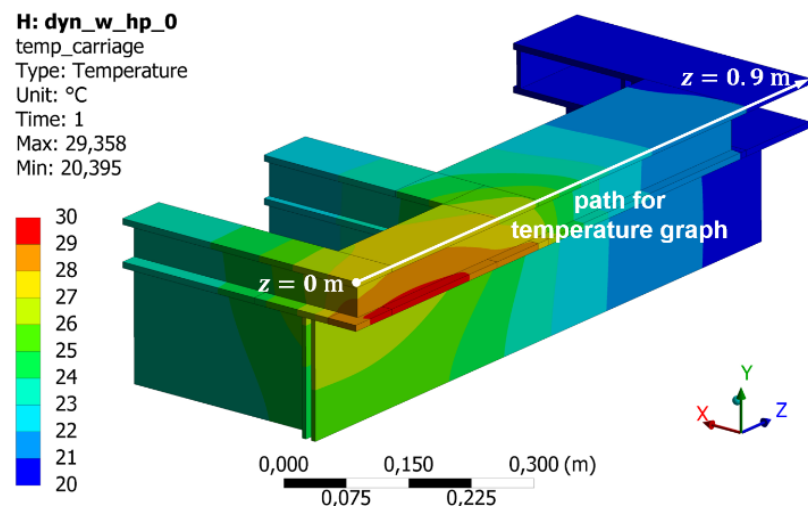

Fig. 13: Simulation results of the temperature field of the carriage for horizontal heat pipe orientation.

Figure 13 illustrates the temperature field of the carriage at steady state for the horizontal heat pipe representation. The temperatures for the different heat pipe scenarios were evaluated along the upper edge of the carriage in zdirection. 


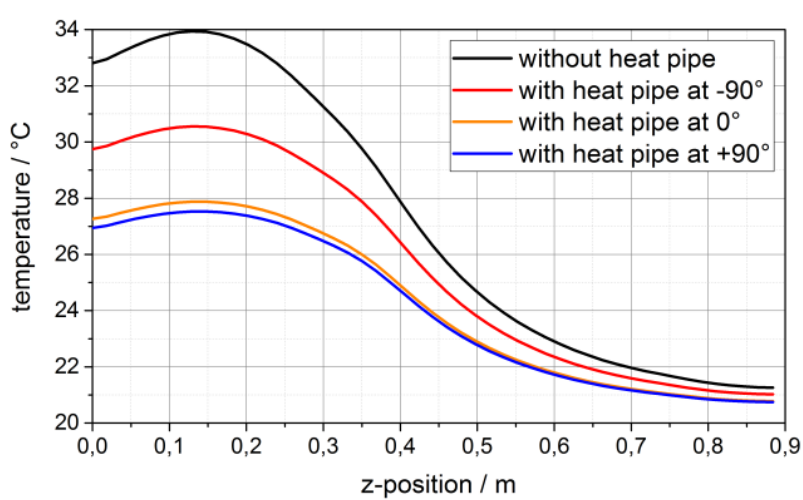

Fig. 14: Temperature profile along the evaluation path of the carriage edge for different simulation cases.

Figure 14 demonstrates the calculated temperature profiles for the three different heat pipe inclination cases as well as the reference case without attached heat pipes. It can be seen, that the heat pipes at $\delta=+90^{\circ}$ and $\delta=0^{\circ}$ effectively transport heat to the heat sink leading to a decrease of the maximum carriage temperature of $6 \mathrm{~K}$. The heat pipe model at $\delta=-90^{\circ}$ leads to a temperature drop of around $3.5 \mathrm{~K}$.

The results indicate that temperatures of moving machine parts can be effectively reduced by means of heat pipe based systems. However, further research is needed to evaluate the impact of the reduced temperatures on the thermoelastic deformations of the machine tool components.

\section{CONCLUSIONS}

This paper presents an approach for thermal control in machine tools using heat pipes. It has been demonstrated, how heat pipes can be thermally characterized by means of an experimental set-up. A heat pipe modelling approach has been proposed that uses the experimentally obtained thermal resistances and is easy to implement in FE models. Different scenarios for the application of heat pipes for thermal control in machine tools have been discussed. One concept was numerically investigated using a simplified FE model of a machine tool carriage. The computational results confirm the efficacy of the corresponding concept. Prospectively, heat pipe based compensation components are to be designed and experimentally verified.

\section{ACKNOWLEDGMENTS}

The authors would like to thank the German Research Foundation (DFG) for financial support within the Collaborative Research Centre Transregio 96.

\section{REFERENCES}

[Baumler 2011] Baumler, S., Bode, H., Brecher, C., Breitbach, T., Hansch, S., Hennes, N., Prust, D., Tannert, M., Thoma, C., Wagner, P., Witt, S. and Würz, T. Ressourceneffizienz im Werkzeugmaschinenbau. In: Brecher, C., Klocke, F., Schmitt, R., Schuh, G. (eds.) Wettbewerbsfaktor Produktionstechnik: Aachener Perspektiven, Proceedings of Aachener Werkzeugmaschinenkolloquium, 2011.

[Brecher 2012] Brecher, C., Baumler, S., Jasper, D. and Triebs, J. Energy Efficient Cooling Systems for Machine Tools. In: Dornfeld D., Linke B. (eds) Leveraging
Technology for a Sustainable World, 2012. Springer, Berlin, Heidelberg.

[Denkena 2018] Denkena, B., Bergmann, B., Klemme, H. and Dahlmann, D. Cooling potential of heat pipes and heat exchangers within a machine tool spindle. In: Ihlenfeldt, S., Brecher, C., Putz, M. and Billington, D. (eds) Conference on Thermal Issues in Machine Tools: Proceedings, 2018, 1st edn. Wissenschaftliche Scripten, Auerbach/Vogtland, 295-305.

[El-Nasr 1996] El-Nasr, A. and El-Haggar, S. Effective thermal conductivity of heat pipes. Heat and Mass Transfer, 1996, Vol.32, 97-101.

[Fraser 1998] Fraser, S., Attia, M.H. and Osman, M.O.M. Modelling, Identification and Control of Thermal Deformation of Machine Tool Structures, Part 1: Concept of Generalized Modelling. Journal of Manufacturing Science and Engineering, August 1998; Vol.120, No.3, 623-631.

[Gnielinski 2006] Gnielinski, V. Warmeubergang bei der Stroemung laens einer ebenen Wand. In: VDI-Warmeatlas, 2006, Springer, Berlin, Heidelberg, 576-580, ISBN 978-3540-32218-4

[Jedrzejewski 1992] Jedrzejewski, J. and Modrzycki, W. Thermal Displacements Compensation of Manufacturing Cells Using a Universal Correcting Temperature Function. Proceedings of CSME Forum, 1992, 675-680.

[Judd 1994] Judd, R.L., Aftab, K. and Elbestawi, M.A. An investigation of the use of heat pipes for machine tool spindle bearing cooling. International Journal of Machine Tools and Manufacture, 1994, Vol.34, 1031-1043, ISSN 0890-6955

[Klan 2006] Klan, H. Waermeubergang durch freie Konvektion an umstromten Koerpern. In: VDIWaermeatlas, 2006, Springer, Berlin, Heidelberg, 530-535, ISBN 978-3-540-32218-4

[Kono 2019] Kono, D., Mizuno, S., Muraki, T. and Nakaminami, M. A machine tool motorized spindle with hybrid structure of steel and carbon fiber composite. CIRP Annals, 2019, Vol.68, No.1, 389-392, ISSN 0007-8506

[Mayr 2012] Mayr, J.; Jedrzejewski, J.; Uhlmann, E.; Donmez, M.A.; Knapp, W., Haertig, F. et al. Thermal issues in machine tools. CIRP Annals, 2012, Vol.61, No.2, 771791.

[Pastukhov 2007] Pastukhov, V.G. and Maydanik, Y.F. Low-noise cooling system for PC on the base of loop heat pipes. Applied Thermal Engineering, 2007, Vol.27, 894901.

[Pohlhausen 1921] Pohlhausen, E. Der Waermeaustausch zwischen festen Koerpern und Fluessigkeiten mit kleiner reibung und kleiner Waermeleitung. Journal of Applied Mathematics and Mechanics, 1921, Vol.1, No.2, 115-121.

[Putz 2018] Puth, M., Richter, C., Regel, J. and Bräunig, M. Industrial consideration of thermal issues in machine tools. Production Engineering, 2018, Vol.12, 723-736.

[Ramesh 2000] Ramesh, R., Mannan, M.A. and Poo, A.N. Error compensation in machine tools - a review. Part II: thermal errors. International Journal of Machine Tools and Manufacture, 2000, Vol.40, 1257-1284.

[Reay 2014] Reay, D., McGlen, R. and Kew, P. Heat pipes. Theory, design and applications. Sixth edition, 2014. Elsevier, Amsterdam. ISBN 978-0-08-098266-3

[Schneider 2016] Schneider, D., Lauer, M., Voigt; I. and Drossel, W.-G. Development and examination of switchable heat pipes. Applied Thermal Engineering, 2016, Vol.99, 857-865. 
[Thiem 2017] Thiem, X., Kauschinger, B. and Ihlenfeldt, S. Structure Model Based Correction of Thermally Induced Motion Errors of Machine Tools. Procedia Manufacturing, Vol.14, 2017, 128-135, ISSN 2351-9789

[Vasiliev 2005] Vasiliev, L.L. Heat pipes in modern heat exchangers. Applied Thermal Engineering, 2005, Vol. 25, $1-19$.

[Voigt 2018] Voigt, I., Winkler, S., Werner, R., Bucht, A. and Drossel, W.-G. Thermal error compensation on linear direct drive based on latent heat storage. In: Ihlenfeldt, S. Brecher, C., Putz, M. and Billington, D. (eds) Conference on Thermal Issues in Machine Tools: Proceedings, 2018, 1st edn. Wissenschaftliche Scripten, Auerbach/Vogtland, 117-126.
[Voigt 2019] Voigt, I., Navarro de Sosa, I., Wermke, B., Bucht, A. and Drossel, W.-G. Increased thermal inertia of ball screws by using phase change materials. Applied Thermal Engineering, 2019, Vol.155, 297-304. ISSN 13594311

[Wegener 2017] Wegener, K., Mayr, J., Merklein, M., Behrens, B.-A., Aoyama, T., Sulitka, M., Fleischer, J., Groche, P., Kaftanoglu, B., Jochum, N. and Möhring, H.-C. Fluid elements in machine tools. CIRP Annals, Vol.66, 2017, 611-634, ISSN 0007-8506

[Zuo 1998] Zuo, Z.J. and Faghri, A. A network thermodynamic analysis of the heat pipe. International Journal of Heat and Mass Transfer, 1998, Vol.41, No.11, 1473-1484, ISSN 0017-9310. 